\title{
EI CINE FORO COMO HERRAMIENTA ESTRATÉGICA APLICADO A LA EDUCACION SUPERIOR: DESCRIPCIÓN DE UNA EXPERIENCIA
}

\author{
Ana María Cóndor Pérez \\ Universidad Ricardo Palma \\ dora_2022@yahoo.es
}

El presente artículo se basó en la puesta en marcha de una efectiva herramienta metodológica de enseñanza, como lo es: el Cine foro. Esta idea nació a partir de la reflexión de un equipo de docentes del Programa de Estudios Básicos, debido a que la orientación de esta herramienta puede fácilmente responder a una diversidad de temáticas propias de cada asignatura, así como a la necesidad de confrontar el contenido temático de los sílabos con la realidad aplicada al entorno cotidiano, considerando la realidad espacio-temporal que ofrece cada film. Finalmente la propuesta genera valor por la trascendencia formativa en nuestros alumnos e inspira a las demás asignaturas a sumarse a la práctica de esta herramienta educativa.

\section{INTRODUCCIÓN}

Cuando un auditorio se encuentra observando una película en el Cine se convierte en receptor de mensajes que no son totalmente claros, desde ese punto de vista se hace necesario un análisis que le permita descubrir el mensaje (que se recibe a través de la vista y el oído), lo plasme claramente y lo lleve a un plano consciente, en donde podrá relacionarlo con su propia vivencia y generar de su parte una interacción con la obra.

Llevando esto hacia el campo educativo, se debe de aprovechar las ventajas del Cine, que atrae la atención del alumnado a quienes lograremos 
educar y recrear a través de un film, el cual será motivo de una reflexión posterior generando un intercambio de ideas y un debate, lográndose así la puesta en marcha de un Cine foro. Debe tenerse claro que el Cine foro es una actividad grupal, por lo que debe ser atractiva y no improvisada, la película debe ser seleccionada cuidadosamente y debe prestarse a un análisis racional cumpliendo con su rol netamente educativo.

\section{PRIMER CINE FORO EN EL PROGRAMA DE ESTUDIOS BÁSICOS}

El Cine foro, se considera un recurso que nos permite apreciar la esencia del cine y el arte; y a su vez brinda un gran potencial formativo en los ámbitos de cultura, ciencias, moral, psicología, filosofía, ideologías, etc. Estas cualidades, lograron luego de un análisis interno, que se decida por esta herramienta, ya que fácilmente se presta al logro de los objetivos académicos.

Partiendo de este enfoque, el CINE FORO PEB 2017-I, se llevó a cabo con el propósito de analizar una película desde el lente de una asignatura específica, sobre el cual, en un primer momento se realiza un análisis general que conlleva posteriormente a un razonamiento específico. De esta forma, logramos conseguir que el alumnado descubra, interiorice y perciba la realidad, relacionándola a la vez con las asignaturas que se imparten en el Programa de Estudios Básicos.

El "Cine Foro PEB" se realizó en Mayo y Junio del 2017 con la participación de las siguientes asignaturas:

1. Historia de la Civilización con el film: "55 Días en Pekín"

2. Formación Histórica del Perú con el film: "Túpac Amaru"

3. Lógica con el film: "El Código Enigma"

4. Recursos Naturales y Medio Ambiente con el film: "Erin Brockovich"

\section{METODOLOGÍA}

Una vez identificada la necesidad de encontrar una herramienta educativa que logre favorecer el análisis de una realidad o un tema concreto, 
la cual es definida por cada asignatura, se procede a elaborar la propuesta a la dirección del Programa de Estudios Básicos señalando el objetivo, la metodología y los beneficios. Una vez aprobado, se estructura el equipo de trabajo, a quienes se designó funciones y responsabilidades, entre ellas:

- Definir el Plan.

- Preparar el cronograma de actividades.

- Identificar los cursos que participarán.

- Comunicar e invitar a los coordinadores a que participen del proyecto.

- Programar reuniones con cada coordinador de curso para detallar la metodología a utilizar, que elija un film que permita el análisis de un tema específico.

- Ubicar y reservar un auditorio con multimedia apropiado.

- Prueba técnica del auditorio y verificar que el film esté en el formato adecuado.

- Diseñar y preparar el material publicitario: banner, dípticos, diseño en hoja A3, material publicitario.

- Elaborar una ficha evaluativa sobre el film.

- Motivar la participación tanto a los profesores como a los alumnos.

- Designar el tiempo para comentarios.

- Preparar y entregar de certificados.

\section{CONSIDERACIONES}

La base de nuestro cine foro es el alumnado a quien va dirigida la proyección y al tema que el docente encargado de la asignatura quiera abarcar. Una vez definido se programa la película; la cual debe considerar:

Que el alumnado no es homogéneo y se debe partir de la diferencia para así lograr acertar con la programación.

El idioma es fundamental determinar en qué idioma se puede proyectar. Para un mejor desarrollo el Programa de Estudios Básicos presenta obras de habla hispana o dobladas. Aunque muchas de las obras audiovisuales a las que se tiene acceso están en idiomas distintos al español y subtituladas.

La temática que se quiera desarrollar a través del film forma parte y complementa el proceso educativo, por tanto el docente está atento a lo que 
le interesa comunicar con la película que eligió, y lo utiliza como punto de partida del cine foro.

\section{DESARROLLO}

\section{Preámbulo:}

El moderador da inicio al Cine foro comunicando antes de la proyección el tema principal que se va a analizar a través del film, el cual es propuesto por cada asignatura; señalando también el objetivo de la discusión o debate para que durante la misma el alumnado esté atento y pueda ir generando sus propias ideas. En esta etapa, que dura unos 20 minutos, es necesario mencionar el nombre del director, el país de origen de la obra, el año y el por qué destacó este film. cumplir:

El moderador también debe tener claro algunas funciones que debe

- Indicar las normas que regularán la participación de los asistentes.

- Presentar a los ponentes.

- Establecer el tiempo de los comentarios y el de la elaboración de preguntas.

\section{La proyección:}

En este espacio, antes de proyectar el film, soltamos una pregunta que promueva la curiosidad acerca del film. Esta actividad tiene como objetivo hacer que los alumnos se relajen.

El moderador inicia la presentación del film, el cual dura unos 100 minutos aproximadamente, debiendo garantizar una óptima condición técnica; esencial para el deleite de una obra audiovisual, tanto la calidad de la proyección y el sonido deben ser impecables; así se hace más agradable la experiencia del alumnado y su disposición para repetirla y convertirla en hábito.

\section{El foro:}

Se procede a concluir el film y dar inicio al comentario de los ponentes. En este momento ya se tiene previsto enfocar uno o varios temas, de tal manera que el alumnado se inclina a la exploración de los mismos a través del intercambio de ideas. 
El método que se usa para el análisis del film es el deductivo, es decir, ir de asuntos generales a temas puntuales (qué nos enseña o como se aplica a una situación determinada).

Luego del comentario de los ponentes se efectúan las preguntas de análisis y reflexión, controlando de no excederse del tiempo establecido que son 45 minutos aproximadamente.

Aprovechamos este espacio también para alfabetizar al alumnado en el dominio de códigos y lenguajes expresivos de este medio, es decir, que no solo conozcan el lenguaje del cine, sino que también interpreten y vean más allá de la información que reciben, la hagan propia y útil para ellos.

Para una óptima implementación del cine foro y de acuerdo con los intereses del alumnado o del docente se puede hacer uso de distintos elementos que contribuyan y dinamicen el espacio como por ejemplo: la lectura de un texto relacionado con el tema principal, bien sea un texto publicado o inédito, uso de fotografías, o que se considere la participación de un personaje ligado directamente con el tema a tratar, etc.

\section{Finalización:}

- El moderador debe dar por finalizado el intercambio de ideas.

- Presenta un resumen de las opiniones expuestas y expone las posibles conclusiones.

- Cierra el foro. El tiempo total de toda la presentación dura en promedio 160 minutos.

\section{ANÁLISIS ESTRATÉGICO}

Como todo proyecto, se hace necesario un análisis de todos los aspectos que forman parte de esta actividad, resumiéndose en lo siguiente:

\section{Fortalezas:}

- Compromiso y apoyo permanente de la dirección.

- Profesores identificados con el proyecto.

- Entusiasmo del equipo de trabajo.

- Auditorio apropiado para el óptimo desarrollo del evento. 


\section{Oportunidades:}

- Se inició con cuatro asignaturas, las que contaron con gran aceptación de docentes y alumnos.

- Al cumplir con el propósito educativo propuesto se proyecta una mayor participación en los próximos ciclos.

\section{Debilidades:}

- Algunos films eran extensos.

- Comentarios prolongados.

- Algunos horarios complicados para el alumnado, pues interferían con otros cursos.

- Falta de una permanente convocatoria de alumnos.

\section{Amenazas:}

- Disponibilidad de auditorio

\section{ANÁLISIS DE LOS RESULTADOS OBTENIDOS}

Al poner en práctica las ventajas que nos ofrece el Cine foro, comprobamos que es una excelente estrategia didáctica que permite realizar un debate guiado entre profesores y alumnos. Esto se vió reflejado en la participación activa del alumnado en todo el proceso.

Importante mencionar que la convocatoria de alumnos a través de los profesores y de la publicidad impresa resultó efectiva, ya que contamos con un lleno total en la mayoría de presentaciones.

El foro empezó con un análisis general para luego llegar al tema específico que cada asignatura se había propuesto enfocar, logrando concientizar al alumnado sobre la problemática en cuestión. Esto, a su vez generó pensamientos y reacciones que fueron canalizadas y tomadas en cuenta para el momento del debate. Finalmente, los alumnos lograron internalizar el mensaje satisfactoriamente y que se vio plasmado luego en clases cuando se tocó el tema a profundidad.

En la parte técnica, cabe señalar que el evento se llevó a cabo en un auditorio con infraestructura adecuada que permitió el normal 
desenvolvimiento de la actividad. Es necesario también que el material audiovisual sea óptimo tanto en calidad de imagen y audio.

El equipo de docentes que participó estuvo conformado por profesionales de alto nivel y trayectoria certificada, quienes lograron trascender con su mensaje e ir más allá de la obra audiovisual. Y como reconocimiento a su valioso aporte formativo, se les hizo entrega de un certificado de participación emitido por el Programa de Estudios Básicos.

Se contó con el apoyo permanente de la dirección del Programa de Estudios Básicos, la cual donó gentilmente revistas académicas para los alumnos que participaron en los comentarios y debate post film.

\section{En términos de mejora:}

- Es conveniente hacer el recordatorio de las fechas del evento tanto a docentes y alumnos, con énfasis en la semana previa.

- Establecer un tope de duración para cada film.

- Delimitar el tiempo destinado para los comentarios.

- Reservar el auditorio con mayor antelación.

\section{VENTAJAS DEL CINE FORO}

Las ventajas más importantes que esta estrategia ofrece son:

- El docente selecciona los temas a tratar en función a la asignatura que se requiere analizar (dirige la acción formativa).

- Alienta el aprendizaje por descubrimiento.

- Promueve el debate.

\section{CONCLUSIONES}

Finalmente se decidió poner en práctica el Cine foro debido a que es una herramienta que permite: 
- Una libre expresión de ideas y opiniones de los alumnos participantes.

- La discusión de cualquier tema que cada asignatura decida enfocar.

- Formula una ó varias preguntas concretas y estimulantes referidas al tema.

- Limita el tiempo de las exposiciones y/o comentarios.

El cine foro se presta a que cada vez que miramos un film enlazamos de manera inconsciente la historia que está siendo contada con nuestra propia historia y en un ambiente relajado donde la charla fluye y los alumnos se olvidan que están en un grupo, suelen manifestarse los más diversos sentimientos los cuales podemos aprovechar para enfocarlos en el tema que buscamos tratar. En ese sentido es que esta herramienta se presta para dinámicas de grupos muy beneficiosas.

Al dirigir el cine foro es importante estar receptivo frente a las expectativas que los alumnos generen, ya que una problemática ó un tema planteado inicialmente puede generar otros y esto debe ser considerado e incluido en el ejercicio, de esta forma podremos lograr un espacio favorable de reflexión.

Es indudable de que con esta estrategia puede realizarse una variedad de actividades. Pero es necesario saber que una película utiliza técnicas que hay que conocer, descubrir e interpretar y, si es posible, investigar sobre su entorno, sus características principales y orientarla a situaciones didácticas relacionadas con conocimientos específicos de cada asignatura que se ofrece en el Programa de Estudios Básicos.

\section{REFERENCIAS BIBLOGRÁFICAS}

Arneim, R. (1986). El cine como arte. Barcelona. Ed. Paidos S.A.

Bedoya, R. (2009). Historia de los medios de comunicación en el Perú Siglo XX. Lima. Universidad de Lima.

Bordwell, D. (2002). El arte cinematográfico. Barcelona. Ed. Paidos S.A.

Darley, A. (2002). Cultura visual digital. Barcelona. Ed. Paidos S.A. 
García, L. (1995). Como acercarse al cine. México. Ed. Noriega.

Magny,J. (1992). Vocabularios del Cine. Barcelona. Ed. Paidos S.A.

Martínez, J. (1991). Introducción a la tecnología audiovisual. Barcelona. Ed. Paidos S.A.

Medina, M. (2006). Calidad y contenidos audiovisuales. Pamplona. Universidad de Navarra.

Mendiz, A. (2000). Como se hicieron las grandes películas. Madrid. Ed. Dossat.

Metz, C. (2002). Ensayo sobre la significación en el cine. Barcelona. Ed. Paidos S.A.

Montero. J. (2005). El cine cambia la historia. Madrid. Ed. Rialp. S.A.

Sánchez Noriega, J. (2005). Historia del Cine: Teoría y género cinematográfico. Madrid. Ed. Alianza S.A.

Stam, R. (2001). Teorías del cine: una introducción. Barcelona. Ed. Paidos S.A.

Stam, R. (1999). Nuevos conceptos de la teoría del cine. Barcelona. Ed. Síntesis S.A.

Schmidt, M. (1997). Análisis de la realización cinematográfica. Madrid. Ed. Síntesis S.A.

Zunzunegui, S. (1996). La mirada cercana: microanálisis filmico. Barcelona. Ed. Paidos S.A. 